\title{
A Novel Technique for the Reconstructive Formation of an Annular Hymen in Cases of Postpubertal Imperforate Hymen
}

Atef M. Darwish

$$
\text { تقنية جديدة لترميم غشاء البكارة الحلقي لحالات غشاء البكارة الرتقاء بعد البلوغ }
$$

عاطف محمد درويش

\begin{abstract}
Objectives: Imperforate hymen $(\mathrm{IH})$ is a common genital tract anomaly in women which usually presents after puberty. However, surgical treatment is often considered controversial in religious or conservative communities for sociocultural reasons. This study therefore aimed to assess the efficacy of a novel reconstructive technique involving the preservation of the annular hymen. Methods: This prospective interventional study was performed between July 2013 and October 2019 at the minimally invasive surgery unit of a tertiary university hospital in Egypt. A total of 36 women presenting with primary amenorrhoea and haematocolpus were diagnosed with postpubertal IH. A circular hymenotomy was performed on each patient using a $10 \mathrm{~mm}$ laparoscopy trocar tip and sleeve to form a new annular hymen under general anaesthesia while preserving the annular hymen. The primary outcome measure was the persistence of hymenal patency and integrity at follow-up. The secondary outcome measure included post-operative patient satisfaction and pain relief. Results: The reported technique was feasible in all cases without intraoperative complications. Patency of the reconstructed annular hymen was confirmed at follow-up in all cases; moreover, no intraoperative complications were reported. There was a significant post-operative improvement in pain scores $(P<0.001)$. Both the patients and their parents/guardians reported a high level of satisfaction with the technique. Conclusion: This novel technique for the correction of $\mathrm{IH}$ involving the reconstruction of an annular hymen was found to be a safe, minimally invasive and effective procedure. This technique should be considered a feasible alternative to a conventional hymenotomy as it allows for the resumption of normal hymenal anatomy without overtreatment.
\end{abstract}

Keywords: Congenital Abnormalities; Imperforate Hymen; Hematocolpos; Amenorrhea; Colpotomy; Reconstructive Surgical Procedures; Treatment Outcome; Egypt.

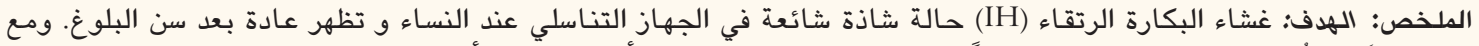

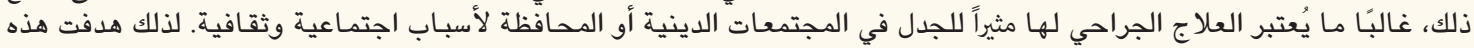

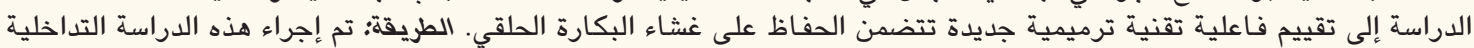

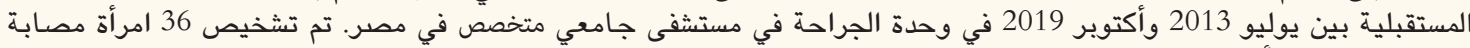

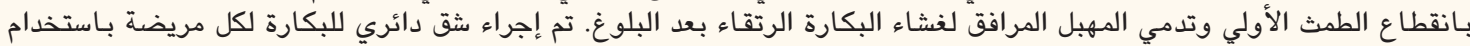

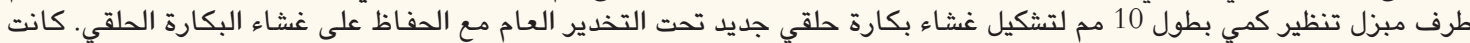

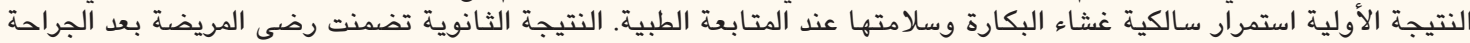

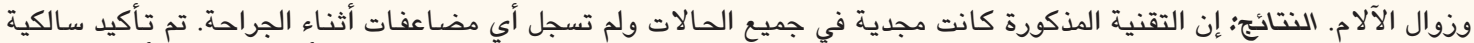

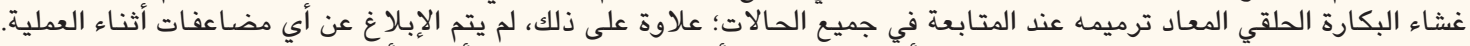

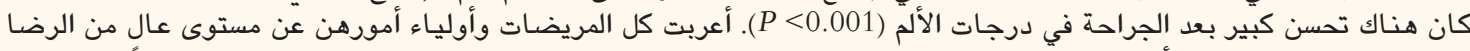

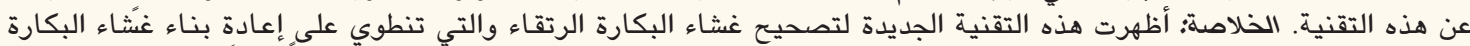

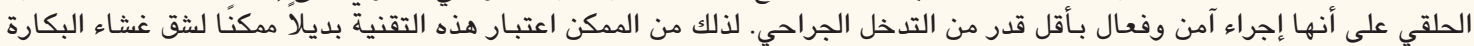

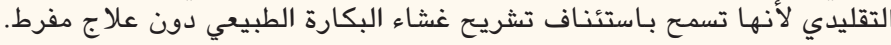

الكلمات المفتاحية: التشوهـات الخلقية؛ غشاء بكارة رتقاء؛ تدمي الههب؛ انقطاع الطمث؛ شق الههبل؛ طرق الجراحة الترميمية؛ نتائج العلاج ؛ مصر.

\section{ADVANCES IN KNOWLEDGE}

This study confirms the safety and efficacy of a novel, simple and minimally invasive technique for the correction of cases of imperforate hymen (IH) involving reconstructive preservation of the annular hymen.

The new technique was found to be successful both from a subjective standpoint in terms of patient satisfaction as well as objectively in terms of symptom relief and annular hymenal patency.

\section{Application to Patient Care}

Based on these findings, this novel technique is recommended as a safe and effective alternative to a classic hymentomy for cases of IH in which the preservation and restoration of the normal hymenal anatomy is a priority. 
$\mathrm{I}$ MPERFORATE HYMEN (IH) IS A COMMON GENITAL tract anomaly reported in approximately one in 2,000 women. ${ }^{1}$ Generally, the obstructive condition presents at menarche when retained menstrual blood and mucosal tissue begins to accumulate in the vagina, resulting in haematocolpos and amenorrhoea, often accompanied by symptoms of abdominal, pelvic and lower back pain, urinary retention, constipation/ tenesmus and uterine distension. ${ }^{2,3}$ A diagnosis of $\mathrm{IH}$ is usually confirmed via clinical examination of the distended hymenal membrane and ultrasonography showing the haematocolpos. ${ }^{3}$ Conventional management of the condition involves the surgical drainage of the retained blood via a hymenotomy in which a vertical, cross or T-shaped incision is made in the hymenal membrane, followed by suturing of the edges to maintain patency and prevent restenosis. ${ }^{3,4}$

However, this traditional surgical approach is often poorly accepted by individuals from religious and conservative communities, resulting in emotional, psychological and even physical deleterious effects due to social stigma and feelings of shame attached to the loss of the hymen and perceived virginity. ${ }^{5-8}$ Moreover, in certain Islamic countries, an official medical certificate is routinely given to the patient to certify that the hymenal defloration occurred as a result of a surgical procedure prior to marriage. ${ }^{8,9}$ In Jordan, for instance, a forensic consultant is required to attend and produce official forensic reports for all gynaecological procedures performed on unmarried Muslim women in order to reassure patients and their parents/guardians of continuing hymenal patency and to protect the rights of both the gynaecologist and patient in case of unavoidable rupture. ${ }^{9}$

Anecdotally, many women diagnosed with $\mathrm{IH}$ along with their parents/guardians express deep concern for the integrity of the hymen and request that the normal hymenal anatomy be preserved as much as possible. Accordingly, this study aimed to describe and evaluate the safety and efficacy of a novel surgical technique for the correction of postpubertal $\mathrm{IH}$ involving the reconstructive formation of a normal annular hymen.

\section{Methods}

This prospective interventional study was conducted between July 2013 and October 2019 at the minimally invasive surgery unit of the Woman's Health University Hospital, Assiut, Egypt. A total of 43 women with primary amenorrhoea and haematocolpus were evaluated. At presentation, the patients complained of various symptoms including a progressive central abdominal mass, worsening pelvic pain, urinary retention, dysuria, constipation and dyschezia, either alone or in combination depending on the degree of retained menses. Only patients with postpubertal IH without other associated congenital anomalies were included in the study. Women with other forms of menstrual irregularities or types of genital tract anomalies were excluded, as were prepubertal cases of $\mathrm{IH}$ due to concerns regarding safety. ${ }^{10}$

All patients underwent a clinical examination to confirm the diagnosis of IH. Initially, a downward labial traction technique was used to separate the labia majora and minora in order to visualise the distal introitus. While in a lithotomy position, a graduated uterine sound instrument was inserted into the vaginal dimple. In four patients, the sound was able to move upwards, thereby indicating a diagnosis of low transverse vaginal septum rather than $\mathrm{IH}$, in which the sound would fail to move upwards. Transverse vaginal septum was differentiated from $\mathrm{IH}$ as the former first requires an operation to fix the edges of the septum to the introitus. ${ }^{10,11}$ In the absence of this prior procedure, a hymenotomy would fail and restenosis would occur due to the thickness of the septum compared to the hymen. ${ }^{11}$ As such, these four cases were excluded from the study.

Subsequently, the hymen was examined for signs of distension and characteristic bluish discolouration while the patient performed the Valsalva respiratory manoeuvre. Two cases of distal vaginal atresia were excluded at this point due to the absence of these signs, as well as the distance between the haematocolpos and the vulva. ${ }^{10}$ In cases where the abdominal mass was deviated to one side, magnetic resonance imaging (MRI) was performed to discount the possibility of type I obstructed hemivagina and ipsilateral renal agenesis (OHVIRA). Only one case of type I OHVIRA (i.e. a blind hemivaginal septum without an opening), presented with primary amenorrhoea due to a rudimentary contralateral horn, was detected and excluded from the study. The diagnosis of $\mathrm{IH}$ was confirmed in the remaining 36 patients based on the characteristic appearance of the dark or bluishcoloured protruding hymenal tissue [Figure 1A] and an ultrasound scan confirming haematocolpos. Further MRI scans to assess the vaginal and perineal region were required only in selected cases in which the diagnosis was ambiguous.

All patients underwent a modified hymenotomy technique with preservation of the annular hymen. To begin with, the patient was placed in the lithotomy position on the operating table. Following the induction of general anaesthesia, the perineum was sterilised and towelled dry. An indwelling urethral catheter was inserted and per-rectal examination 


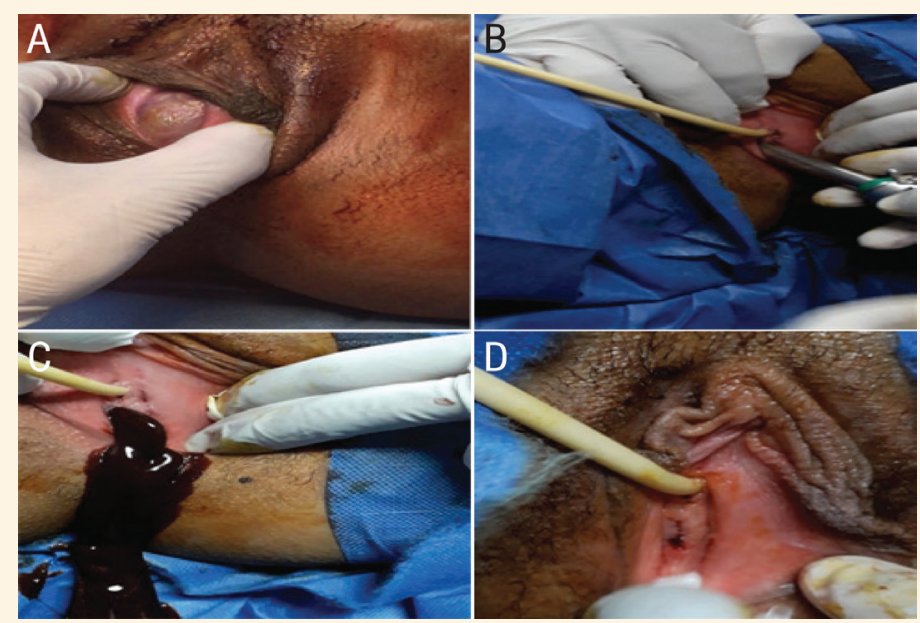

Figure 2:Photographs showing the surgical steps involved in a novel reconstructive technique for cases of postpubertal imperforate hymen involving the preservation of the annular hymen including the (A) characteristic preoperative appearance of the imperforate hymen, (B) perforation of the hymenal membrane using a $10 \mathrm{~mm}$ laparoscopy trocar tip, (C) subsequent release of the retained menses and (D) post-operative integrity and patency of the intact annular hymenal ring without restenosis.

was performed to rule out any other anomalies or abnormalities. Subsequently, the sharp triangular tip of a $10 \mathrm{~mm}$ laparoscopy trocar (Karl Storz SE \& Co. KG, Tuttlingen, Germany) was inserted into the centremost protruding section of the hymenal membrane [Figure 1B]. Once the edge of the sleeve had followed the tip into the hymenal membrane, the tip was not advanced any further to avoid unintentional injury. The trocar was then withdrawn, leaving the sleeve in situ to allow drainage of the retained menses [Figure $1 \mathrm{C}$ ]. No suprapubic pressure was applied to avoid ascending infection from the negative pressure. After the flow of retained menstrual blood and tissue had stopped naturally, the sleeve was removed. In most cases, no further intervention was needed; however, gentle bipolar coagulation was applied if there was continuing discharge.

Thereafter, the remaining hymenal ring was evaluated to determine whether it was still intact and circular. After the surgery, the patient remained in the post-operative ward to recover for a few hours before being discharged. Each patient was advised to return to the hospital for follow-up either after their next menstrual cycle or in 40 days if no menstrual bleeding occurred in the interim. At follow-up, a clinical examination was conducted to ensure the patency and integrity of the hymen [Figure 1D]; in addition, ultrasonography was performed to ensure the absence of haematocolpos and to assess the kidneys. Subsequent follow-up visits were optional and recommended to patients only if they noticed any changes in menstrual flow. Telephone consultations were conducted to collect follow-up data including both objective observations of hymenal ring integrity and subjective reports of patient satisfaction and symptom relief. Self-reported pre- and post-operative pain was assessed using a visual analogue scale (VAS) in which patients drew a mark on a $10 \mathrm{~cm}$ line representing a continuum between no pain (scored as zero) and the worst pain imaginable (scored as 10). The primary outcome measure was the persistence of hymenal patency and integrity at follow-up. The secondary outcome measure included post-operative patient satisfaction and pain relief.

Data analysis was conducted using the Statistical Package for the Social Sciences, Version 19 (IBM Corp., Armonk, New York, USA). Results were presented as frequencies and percentages. Either a Chi-squared test or Fisher's exact test was used to compare qualitative variables. A $P$ value of $\leq 0.050$ was considered statistically significant. Due to the rarity of $\mathrm{IH}$ cases, preoperative and post-operative results were compared for the same patient in each case.

This study was approved by the local ethical committee of the Faculty of Medicine at Assiut University (\#2156521). Informed consent was received from all patients or their legal guardians following a detailed explanation of the study and surgical procedure.

\section{Results}

This study comprised 36 cases with IH. The mean age of the patients was $13.3 \pm 1.9$ years. Primary amenorrhoea and suprapubic pain were the main presenting complaints in all patients. Loin pain and low grade fever were encountered in 15 (41.6\%) and 19 (52.6\%) cases, respectively. A total of 25 women (69.4\%) 
reported being in agonising pain which disturbed their daily activities and was exacerbated on a monthly basis. Haematocolpos was detected in all cases (100\%) upon clinical and ultrasound examination. No intraoperative complications were reported during the current reported technique.

Post-operatively, the patency of the reconstructed hymen was confirmed in all cases (100\%), with a clinical examination revealing an intact annular hymenal ring without restenosis. Recurrence of the haematocolpos was excluded in all cases by high-resolution transabdominal ultrasonography at both the first followup and any subsequent visits. Subjectively, all patients reported a high level of satisfaction with the procedure and the relief of former IH symptoms. There was a significant post-operative improvement in pain VAS score $(P<0.001)$. The possibility of restenosis over a longer period of time was excluded by patient reports during telephone consultations of the resumption of normal menstrual flow.

\section{Discussion}

Although an intact hymen does not necessarily correspond to virginity from a biological perspective, it is often considered indicative of abstinence from premarital sex in many cultures and thus remains intrinsically tied with concepts of familial pride and honour. ${ }^{9,12}$ Indeed, in some countries, unmarried or newly married women without intact hymens can face severe social consequences ranging from humiliation to ostracism, divorce and even extreme violence or abuse, for instance as a result of corporal punishment (i.e. stoning or lashes), execution or honour killings. ${ }^{6,7}$ As a result, in many Islamic and other conservative communities, conventional hymenectomy procedures are often considered unacceptable due to the inherent surgical risk of hymenal rupture. ${ }^{5-9}$

While it is often challenging for individuals from other cultures to fully understand or accept the importance placed on hymenal integrity in these communities, it remains a critical sociocultural and psychological issue, particularly for young adolescent girls with medical conditions or genital abnormalities such as IH. It is therefore essential that medical practitioners endeavour to respect these cultural beliefs and take measures to ensure the integrity of the hymen as much as feasibly possible. ${ }^{9}$ To this end, the American College of Obstetricians and Gynecologists recently stated that elective vulvar cosmetic surgery should be offered to women to alleviate anxiety, depression and other psychiatric conditions resulting from hymenal rupture. ${ }^{13}$
From a medical standpoint, postpubertal $\mathrm{IH}$ can result in serious complications if left untreated, such as secondary endometriosis, hydronephrosis, haematosalpinx rupture, renal failure, lymphovenous obstruction and infection. ${ }^{3,14}$ The primary goal of IH management is to achieve hymenal patency, an objective usually accomplished via conventional hymenotomy. ${ }^{3,4}$ However, the subsequent loss of hymenal integrity can be avoided with concomitant reconstructive surgery to restore the normal anatomy of the hymen. Moreover, there is no need to provide the patient with a medical report to certify hymenal defloration as the post-operative annular hymen mimics the normal hymen in terms of both appearance and function.

Various approaches to surgical IH management have been described in the literature. In most cases, the correction of clinically significant hymenal variations involves the excision of the hymenal tissue and the redundant mucosa. ${ }^{10}$ However, the simple incision and drainage of haematocolpos in a patient with $\mathrm{IH}$ should be avoided due to the risk of ascending infection and sepsis. ${ }^{15}$ Other researchers have recommended surgical resection be performed for thicker hymenal membranes, whereas a vertical incision can be applied to thinner membranes. ${ }^{10}$ In addition, fixing the vaginal wall to the introitus can help to avoid restenosis and the development of post-operative complications. ${ }^{10,14}$ In a recent literature review, Lee et al. reported that most IH patients were treated surgically (83.5\%), most often via hymenotomy (35.2\%) or hymenectomy (36.4\%), without significant differences in outcome. ${ }^{16}$ However, previous research has indicated the possibility of $\mathrm{IH}$ restenosis following a hymenectomy. ${ }^{17}$

Alternative methods of treating $\mathrm{IH}$ without affecting hymenal integrity have also been proposed. For example, some researchers have described a technique in which the hymenal membrane can be opened via a 0.5 $\mathrm{cm}$ central oval incision using a scalpel, followed by the insertion of an inflated 16F Foley catheter left in place for two weeks to prevent re-adhesion of the edges. ${ }^{18,19}$ However, maintaining a catheter in a cavity filled with retained menses for long periods of time is very risky and can potentially result in pelvic inflammatory disease. ${ }^{10,20}$ Moreover, the use of a scalpel to create an incision can result in an opening with irregular edges due to fine tremors in the hands of the surgeon, which can be influenced by different factors such as anxiety, stress or urgency. ${ }^{21}$ In contrast, the current reported technique was found to result in the formation of an even and wide hymenal opening, while still preserving the annular hymen.

Furthermore, a reusable laparoscopy trocar is a dual-function medical instrument readily available 
in most gynaecological operating rooms of tertiary hospitals without the need for additional expenses or healthcare resources. Although it can be claimed that scalpels are more readily accessible, it should be noted that the diagnosis and treatment of IH cases should take place exclusively at specialised tertiary centres due to the risk of misdiagnosis with other lower genital congenital anomalies, such as low transverse vaginal septum, agenesis of the lower third of the vagina and OHVIRA. ${ }^{10}$ An accurate diagnosis is crucial as inappropriate interventions may result in serious complications as well as incomplete treatment. For this reason, only postpubertal patients were included in the current study. The onset of estrogenisation at puberty allows for a clearer examination of the perineal anatomy as well as recognition of characteristic symptoms, thus reducing the likelihood of misdiagnosis. Moreover, the hymen can be more easily stretched due to the estrogenisation of the vaginal tissue without the risk of spontaneous rupture. ${ }^{15}$

As such, a hymenectomy is sometimes recommended to ensure persistent patency. Histologically, the bulk of the hymen is formed of a connective tissue formed of partly elastic and partly collagenous fibres. ${ }^{22}$ Both surfaces are covered by a stratified squamous epithelium which lacks any evidence of cornification or glandular or muscle elements and without nerve cells and fibres at the free edge. As such, the hymen is easily perforated upon penetration and usually retracts laterally due to the absence of muscle elements. These facts support the use of a laparoscopy trocar tip in the current study, with immediate retraction of the fibrous membrane observed following withdrawal of the laparoscopic sleeve. In addition, no cases of restenosis were identified in any of the patients at either the first or subsequent follow-up visits.

Certain limitations to the present study should be acknowledged, including the lack of a comparison group and the relatively small sample size. Both of these limitations are due to the rarity of $\mathrm{IH}$ cases. In addition, the study was restricted to postpubertal cases for reasons of safety and to ensure the accuracy of the diagnosis. Finally, objective preoperative assessment of the psychological status of the patients was difficult in many cases due to their young age, high levels of pain and the atmosphere of stress, fear and anxiety surrounding the concept of hymenal integrity. However, while any research involving a novel procedure for patients with rare conditions will be subject to methodological limitations, the data from the present study may nevertheless be helpful in generating a hypothesis that can be tested in further analytic studies. $^{23}$

\section{Conclusion}

The current study described a novel, minimally invasive approach for the surgical correction of postpubertal $\mathrm{IH}$ involving the formation of a new orifice using a laparoscopy trocar and the reconstruction and preservation of an annular hymen. This technique was found to be both safe and effective, resulting in high levels of patient and family satisfaction. As such, this approach should be considered in circumstances where resumption of the normal anatomy of the hymen is a matter of considerable sociocultural and psychological importance.

\section{CONFLICT OF INTEREST}

The author declares no conflicts of interest.

\section{FUNDING}

No funding was received for this study.

\section{References}

1. Schorge JO, Schaffer JI, Halvorson LM, Hoffman B, Bradshaw K. Anatomic disorders. In: Williams Gynecology, 1st ed. New York, USA: McGraw Hill Medical, 2008. Pp. 412-13.

2. Dane C, Dane B, Erginbas M, Cetin A. Imperforate hymen-A rare cause of abdominal pain: Two cases and review of the literature. J Pediatr Adolesc Gynecol 2007; 20:245-7. https://doi.org/10.10 16/j.jpag.2006.12.003

3. Mwenda AS. Imperforate hymen - A rare cause of acute abdominal pain and tenesmus: Case report and review of the literature. Pan Afr Med J 2013; 15:28. https://doi.org/10.11604/ pamj.2013.15.28.2251.

4. Rathod S, Samal SK, Rajsekaran A, Rani PR, Ghose S. Imperforate hymen and its complications: Report of two cases and review of literature. Int J Reprod Contracept Obstet Gynecol 2014; 3:839-42. https://doi.org/10.5455/2320-1770.ijrcog20140965.

5. Moaddab A, McCullough LB, Chervenak FA, Stark L, Schulkin J, Dildy GA, et al. A survey of honor-related practices among US obstetricians and gynecologists. Int J Gynaecol Obstet 2017; 139:164-9. https://doi.org/10.1002/ijgo.12294.

6. Pelin SS. The question of virginity testing in Turkey. Bioethics 1999; 13:256-61. https://doi.org/10.1111/1467-8519.00154.

7. Cook RJ, Dickens BM. Hymen reconstruction: Ethical and legal issues. Int J Gynaecol Obstet 2009; 107:266-9. https://doi. org/10.1016/j.ijgo.2009.07.032.

8. Frank MW, Bauer HM, Arican N, Fincanci SK, Iacopino V. Virginity examinations in Turkey: Role of forensic physicians in controlling female sexuality. JAMA 1999; 282:485-90. https:// doi.org/10.1001/jama.282.5.485

9. Abder-Rahman HA. Hymen care for unmarried Muslim females: Role of the forensic consultant in gynaecology interventions. East Mediterr Health J 2009; 15:861-7.

10. American College of Obstetricians and Gynecologists (ACOG). Diagnosis and management of hymenal variants: ACOG committee opinion number 780. Obstet Gynecol 2019; 133:e372-6. https://doi.org/10.1097/AOG.0000000000003283.

11. Williams CE, Nakhal RS, Hall-Craggs MA, Wood D, Cutner A, Pattison $\mathrm{SH}$, et al. Transverse vaginal septae: Management and long-term outcomes. BJOG 2014; 121:1653-8. https://doi. org/10.1111/1471-0528.12899. 
12. Hegazy AA, Al-Rukban MO. Hymen: Facts and conceptions. theHealth 2012; 3:109-15.

13. American College of Obstetricians and Gynecologists (ACOG). Elective female genital cosmetic surgery: ACOG committee opinion, number 795. Obstet Gynecol 2020; 135:e36-42. https://doi.org/10.1097/AOG.0000000000003616.

14. Nielsen V, Vyrdal C. [Imperforate hymen can cause abdominal pain and primary amenorrhoea]. Ugeskr Laeger 2013; 175:1500-1.

15. Oakes MB, Hussain HK, Smith YR, Quint EH. Concomitant resorptive defects of the reproductive tract: A uterocervicovaginal septum and imperforate hymen. Fertil Steril 2010; 93:268.e3-5. https://doi.org/10.1016/j.fertnstert.2009.10.001.

16. Lee KH, Hong JS, Jung HJ, Jeong HK, Moon SJ, Park WH, et al. Imperforate hymen: A comprehensive systematic review. J Clin Med 2019; 8:56. https://doi.org/10.3390/jcm8010056

17. Ossman AME, El-Masry YI, El-Namoury MM, Sarsik SM. Spontaneous reformation of imperforate hymen after repeated hymenectomy. J Pediatr Adolesc Gynecol 2016; 29:e63-5. https://doi.org/10.1016/j.jpag.2016.02.001
18. Acar A, Balci O, Karatayli R, Capar M, Colakoglu MC. The treatment of 65 women with imperforate hymen by a central incision and application of Foley catheter. BJOG 2007; 114:1376-9. https://doi.org/10.1111/j.1471-0528.2007.01446.x.

19. Kidess EA, Baaqeel HS. The imperforate hymen: A culturally oriented surgical approach. Ann Saudi Med 1988; 8:336-9. https://doi.org/10.5144/0256-4947.1988.336.

20. Wong JWH, Siarezi S. The dangers of hymenotomy for imperforate hymen: A case of iatrogenic pelvic inflammatory disease with pyosalpinx. J Pediatr Adolesc Gynecol 2019; 32:432-5. https://doi.org/10.1016/j.jpag.2019.04.002.

21. Hanrahan J, Sideris M, Pasha T, Tsitsopoulos PP, Theodoulou I, Nicolaides $M$, et al. Hands train the brain-What is the role of hand tremor and anxiety in undergraduate microsurgical skills? Acta Neurochir (Wien) 2018; 160:1673-9. https://doi. org/10.1007/s00701-018-3609-6.

22. Mahran M, Saleh AM. The microscopic anatomy of the hymen. Anat Rec 1964; 149:313-18. https://doi.org/10.1002/ ar.1091490213.

23. Kooistra B, Dijkman B, Einhorn TA, Bhandari M. How to design a good case series. J Bone Joint Surg Am 2009; 91:21-6. https://doi.org/10.2106/JBJS.H.01573. 